\title{
IMPACT OF STYLUS Size IN ROUGHNESS MEASUREMENT
}

\author{
Dana Kubátová*, Martin Melichar, Jan Kutlwašer
}
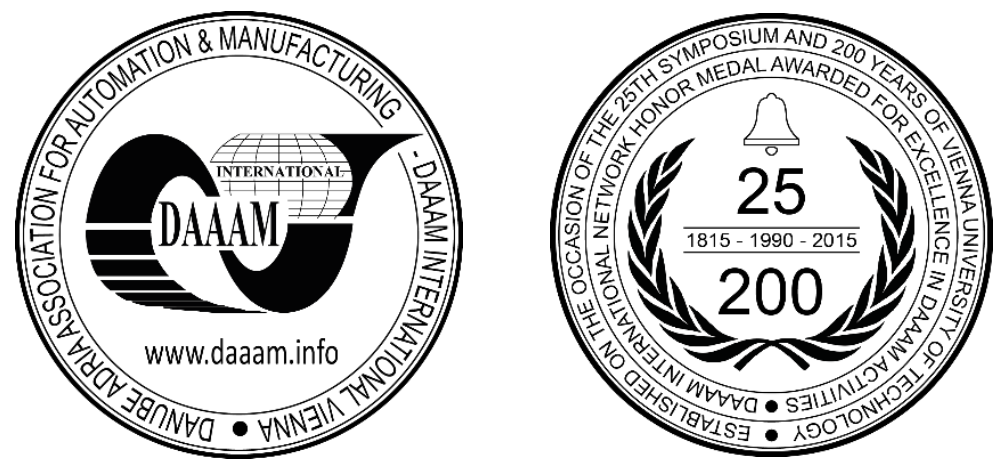

This Publication has to be referred as: Kubatova, D[ana]; Melichar, M[artin] \& Kutlwaser, J[an] (2017). Impact of Stylus Size in Roughness Measurement, Proceedings of the 28th DAAAM International Symposium, pp.0457-0466, B. Katalinic (Ed.), Published by DAAAM International, ISBN 978-3-902734-11-2, ISSN 1726-9679, Vienna, Austria DOI: $10.2507 / 28$ th.daaam.proceedings.064

\begin{abstract}
In technical practice, the concept of surface roughness plays an irreplaceable role. This property has been evaluated by various techniques and mathematical approaches since the 1920s. However, evaluation is often underestimated and reduced to find the $\mathrm{Ra}$ or $\mathrm{Rz}$ parameter. This occurs regardless of methodology. It represents a totally unacceptable simplification of the issue. The following article will clarify a "small" part of this vast issue. Nowadays, there are two basic options for measuring roughness. The first option is the contact method; the second option is the non-contact measurement method. Each method has its advantages and disadvantages and is typically used only for a specific application (2D or 3D roughness measurement). This paper focuses on the contact measurement of $2 \mathrm{D}$ surface area, specifically the choice of the size and shape of the stylus tip. This article maps the problem of choosing a stylus tip in the interval where the standard ISO 4288: 1999 permits usage of both stylus tip sizes. This concerns the roughness range Ra $=0.1 \div 2 \mu \mathrm{m}$ (aperiodic surfaces) and the range of the parameter Rsm $=0.13 \div 0.4 \mathrm{~mm}$ (periodic surfaces). The article further compares the use of a new stylus and an old (worn) one.
\end{abstract}

Keywords: Roughness; Contact and Non-contact measurement; Stylus size and shape; Standard ČSN EN ISO 4288:1999

\section{Introduction}

Measurement and evaluation of surface texture have seen major qualitative advances in recent years. Leading producers of measuring instruments (Hommel, Carl Zeiss, and others) have responded actively to new requirements. Surface texture is frequently checked by means of single-purpose measuring instruments. For this reason, some of the key players who put pressure on developing standards related to evaluating the quality of measurement of machined surfaces are the manufacturers of such instruments themselves. [2]

This has ultimately led to improved technologies of existing tools for surface texture measurement and evaluation, as well as to better methods, measuring systems and the system of assessment and evaluation of surface texture that are still under development. [6; 7] The system of assessment and evaluation of surface texture is defined by a body of standards which describe designations, measurement, and evaluation of surface texture, calibration of measuring instruments, and other aspects. They are the GPS (Geometrical Product Specification) standards. [5]

Generally, the measurement and assessment of surface texture represents a separate field of metrology. Using special techniques, the data required for characterizing the quality of surface can be obtained.

In order to assess the surface quality in an objective manner, relevant information on the surface in question must be obtained by measuring. First, the primary profile must be scanned using a stylus tip. From this profile, individual sets of 
irregularities are then filtered out (roughness, waviness, form of the surface) which comprise the actual surface texture. These irregularities differ predominantly in their spacing and their effects on the surface performance. This is why they must be separated for analysis. [3;8] Components of the surface texture are separated by filtering. In order to determine specific roughness parameters ( $\mathrm{Ra}, \mathrm{Rz}$ and others) from the measured profile (primary profile) of the surface, the roughness component must be separated from other types of irregularities found in the surface. However, when roughness is measured by a contact method, such as in this case, data distortion (filtering) by the probe arm. Just the size of the value distortion from the used tip was detected in the test described in this article.

\section{Measurement of surface roughness by contact method}

The ČSN EN ISO 3274:1998 standard defines a contact instrument as a measuring instrument which explores surfaces with a stylus and acquires deviations in the form of a surface profile, calculates parameters and can record this profile. One of the important components of the instrument is the measurement loop. It is a closed chain which comprises all mechanical components that connect the work piece and the stylus tip.

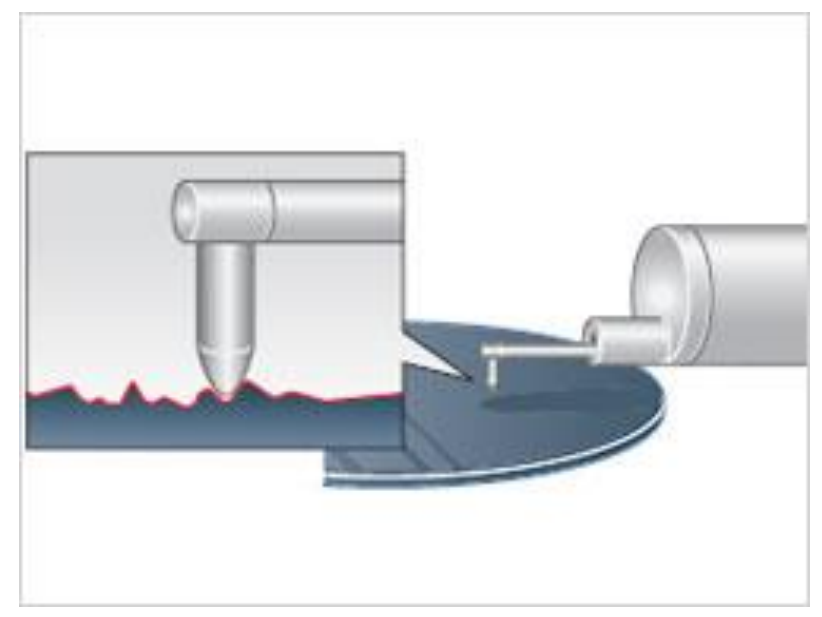

Fig. 1. Stylus [9]

The accuracy of the measurement reading is influenced by the following:

- $\quad$ stylus tip radius

- $\quad$ stylus tip apex angle

- measuring (loading) force

- rate of change of measuring force

In this article, we only focus on the effects of the stylus tip radius. Hence, changes in surface roughness readings obtained with styli of various sizes will be explored. The stylus tip should be pressed against the surface with such a force that it remains in contact with the surface under measurement during the transducer movement. According to the ČSN EN ISO 3274:1988 standard, the ideal stylus shape is a cone with a spherical tip. The nominal radius of the tip is $2 \mu \mathrm{m}$, $5 \mu \mathrm{m}$, or $10 \mu \mathrm{m}$; and the cone apex angle is $60^{\circ}$, or $90^{\circ}$.

\section{Experimental}

Testing was carried out in the Hommel Etamic T8000 machine. Styli of 2 and $5 \mu \mathrm{m}$ with the apex angle of $90^{\circ}$ were fitted to the machine. The tests also included investigation of the impact of using an old (worn) stylus; with both stylus tip sizes. Fig. $3-6$ show electron micrographs of the actual stylus tip shapes.

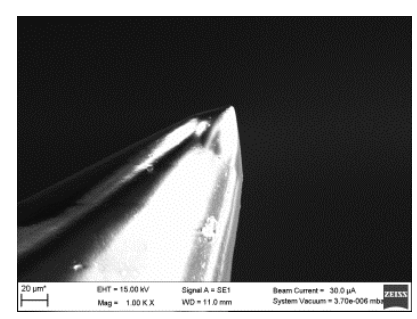

Fig. 2. Old tip 2

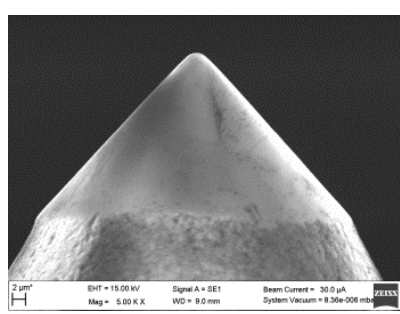

Fig. 3. New tip 2

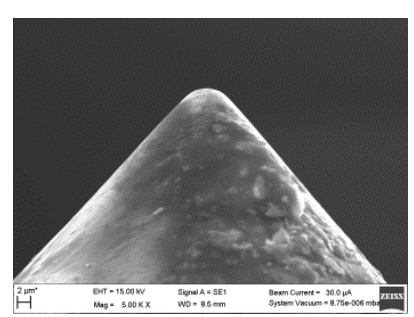

Fig. 4. Old Tip 5

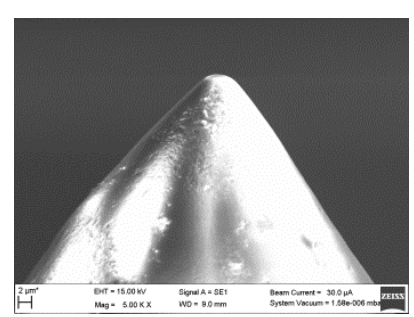

Fig. 5. New tip 5 
The test pieces were roughness standards. Their roughness values were verified through calibration by an independent contractor. [12] These roughness values were chosen so that the experiment takes place within the Rsm parameter (periodic surface) interval in which the use of both sizes of stylus tips is permitted, as indicated in Tab. 1.

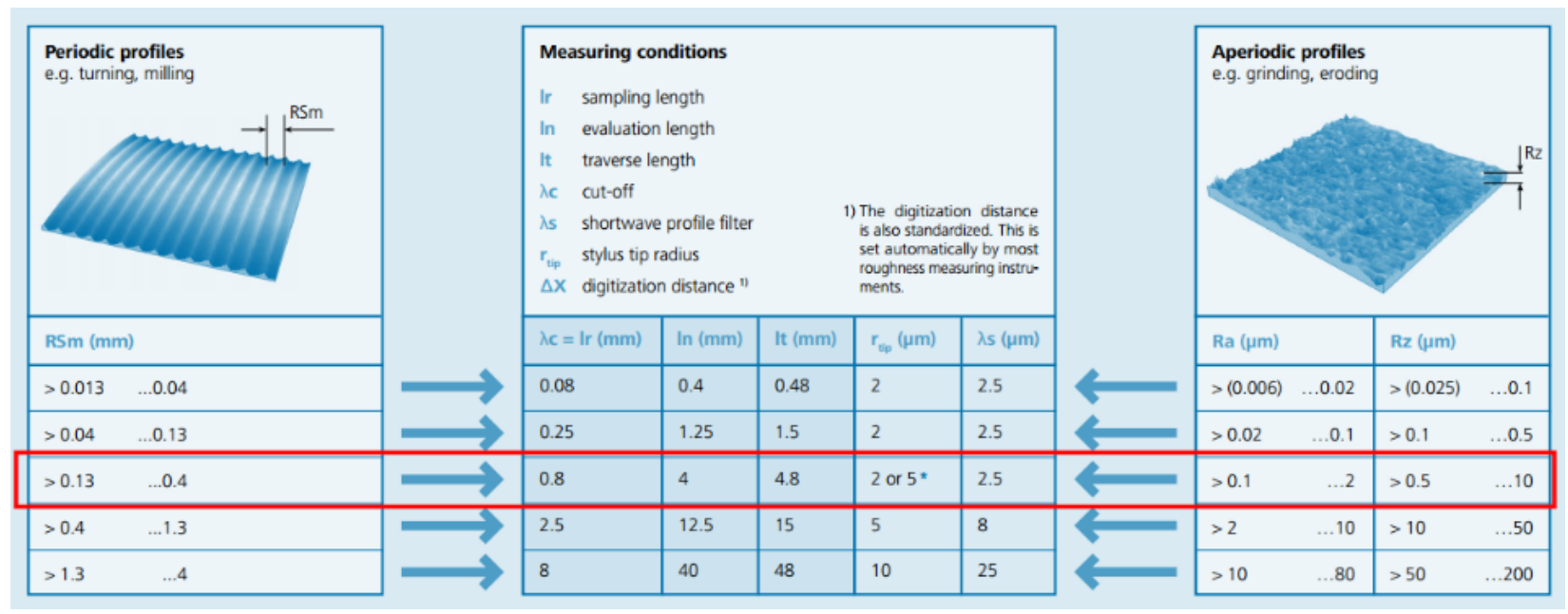

Table 1. Table of values for roughness measurement [10]

Prior to measurement, each reference standard was divided into fields of $10 \times 6 \mathrm{~mm}$ size (Fig. 6). Measurement was then carried out in each of these fields. The paths were arranged not to overlap which was made possible by the machine's precision measuring table. After the standard had been installed in the required position, its movement was effected exclusively by the measuring table. All measurement runs were repeated twice. The pattern of measuring paths started $0.5 \mathrm{~mm}$ from the field's boundary. Each subsequent path was spaced $1 \mathrm{~mm}$ from the previous one $(0.5 ; 1.5 ; 2.5 ; \ldots)$.

\begin{tabular}{l|l|l|l|l|} 
& A & B & c \\
\hline 1 & IIII & IIII & IIII \\
\hline 2 & IIII & IIII & IIII \\
\hline 3 & IIII & IIII & IIII \\
\hline 4 & IIII & IIII & IIII \\
\cline { 2 - 4 }
\end{tabular}

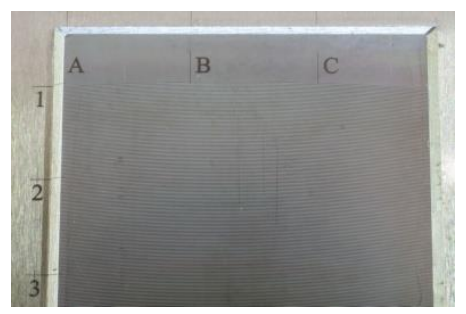

Fig. 2. Segmentation of the standard

In this test, a wide range of roughness parameters relating to all fields were evaluated, including all kinds of profile parameters, roughness parameters and waviness parameters. This article only describes those which are most often used in the automotive industry and aircraft engineering. Their values were calculated using the robust Gaussian filter which leads to the most faithful representation of the acquired profile. More information on filters can be found in articles 13 and 11 .

\section{Processing of results}

The test machine was set up according to information obtained from preliminary tests conducted on individual standards. The set-up parameters were in agreement with the area indicated in red in Table 1. A detailed list is given in Table 2.

\begin{tabular}{|c|c|c|c|c|}
\hline & $\operatorname{Rsm}[\mu \mathrm{m}]$ & Lt [mm] & $\mathbf{L c}[\mathrm{mm}]$ & $\mathbf{r}_{\text {tip }}[\mu \mathrm{m}]$ \\
\hline $\mathrm{Ra} 0.5 \mu \mathrm{m} / \mathrm{Rz}$ & 0.1301 & 4.8 & 0.8 & 2 or 5 \\
\hline $\mathrm{Ra} 1 \mu \mathrm{m} / \mathrm{Rz}$ & 0.254 & 4.8 & 0.8 & 2 or 5 \\
\hline $\mathrm{Ra} 3.2 \mu \mathrm{m} / \mathrm{Rz}$ & 0.408 & 4.8 & 0.8 & 2 or 5 \\
\hline
\end{tabular}

Table 2. Surface roughness tester set-up parameters

Results were evaluated in several steps:

- In the first step, the parameter values were averaged across the entire standard and for the particular stylus tip. These values are plotted in graphs here. 
- In the second step, the percent difference between values of selected parameters were calculated. These were values measured with stylus tips of the same size but different wear levels. The values measured with the new stylus tip were taken as the reference values.

- In the third step, the percent difference between stylus tips with the same wear level but different tip radii was calculated. The reference value was the value measured with the stylus tip of $2 \mu \mathrm{m}$ size.

\subsection{Ra 0.5 standard}

The roughness value $\mathrm{Ra} 0.5 \mu \mathrm{m}$ of this standard is the lowest roughness value used in this test. The surface of the standard is strictly periodic. Prior to measurement, the machine is set up on the basis of the roughness parameter Rsm ("Mean value of the profile element widths within a sampling length." [4]). During preliminary testing, the value Rsm = $0.1301 \mu \mathrm{m}$ was very close to the lower limit of the marked area in Table 1 . Nevertheless, it still met the condition of staying within the interval in which either of the $2 \mu \mathrm{m}$ and $5 \mu \mathrm{m}$ styli can be used.

\subsubsection{Profile parameters}

Since profile parameter results are not distorted by filters, they are good for exploring the effects of mechanical characteristics in the roughness measurement process. The following parameters were chosen:

- $\mathrm{Pt} \quad-$ "Sum of the height of the largest profile peak height and the largest profile valley depth within the sampling length." [4]

\begin{tabular}{|c|c|c|}
\hline & $\mathbf{2} \boldsymbol{\mu m}$ & $\mathbf{5} \boldsymbol{\mu m}$ \\
\hline difference in $\%$ & 21.9752347 & 18.43596647 \\
\hline
\end{tabular}

Table 3. Percent difference between the new and the old stylus tip

\begin{tabular}{|c|c|c|}
\hline & New & Old \\
\hline difference in $\%$ & -3.916264416 & -4.973875115 \\
\hline
\end{tabular}

Table 4. Percent difference between the $2 \mu \mathrm{m}$ and $5 \mu \mathrm{m}$ stylus tips

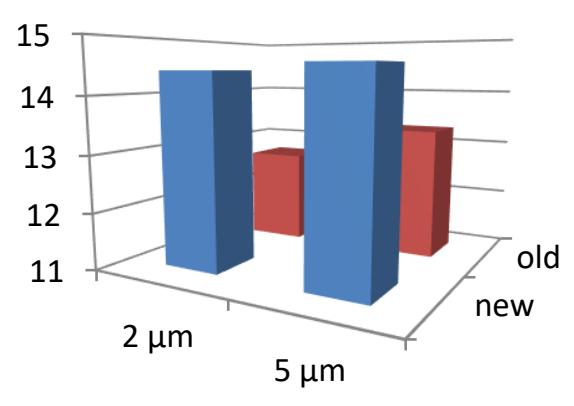

Graph 1. Graphic evaluation of Pt parameter

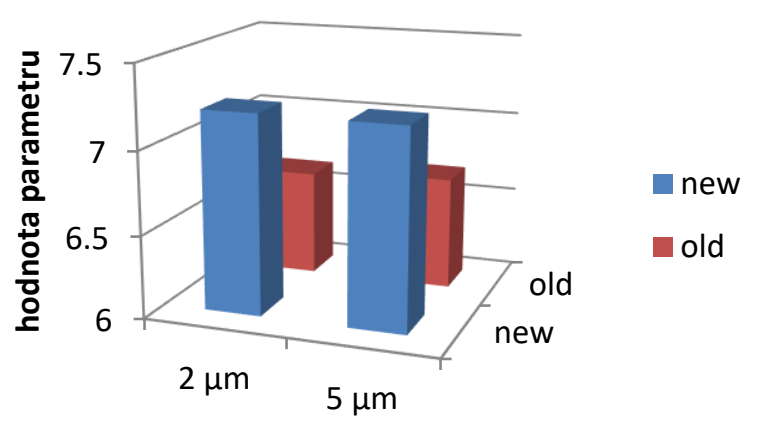

Graph 2. Graphic evaluation of Pa parameter

- Pa - "Arithmetic mean of absolute ordinate values within a sampling length." [4]

\begin{tabular}{|c|c|c|}
\hline & $\mathbf{2} \boldsymbol{\mu m}$ & $\mathbf{5} \boldsymbol{\mu m}$ \\
\hline difference in $\%$ & 17.846048905 & 17.242688875 \\
\hline
\end{tabular}

Table 5. Percent difference between the new and the old stylus tip

\begin{tabular}{|c|c|c|}
\hline & New & Old \\
\hline difference in $\%$ & 0.046245448 & -0.608182275 \\
\hline
\end{tabular}

Table 6. Percent difference between the $2 \mu \mathrm{m}$ and $5 \mu \mathrm{m}$ stylus tips 


\subsubsection{Roughness parameters}

Unlike profile parameters, roughness parameters are subject to distortion by the filter used for their calculation. For this reason, greater emphasis was placed on profile parameters during the processing of results. Despite that, the article reports the effects on two most common roughness parameters.

- Ra - "Arithmetic mean of absolute ordinate values within a sampling length." [4]

\begin{tabular}{|c|c|c|}
\hline & $\mathbf{2} \boldsymbol{\mu m}$ & $\mathbf{5} \boldsymbol{\mu m}$ \\
\hline difference in \% & 5.262520458 & 4.940866367 \\
\hline
\end{tabular}

Table 7. Percent difference between the new and the old stylus tip

\begin{tabular}{|c|c|c|}
\hline & New & Old \\
\hline difference in \% & -0.122749591 & -0.345259897 \\
\hline
\end{tabular}

Table 8. Percent difference between the $2 \mu \mathrm{m}$ and $5 \mu \mathrm{m}$ stylus tips

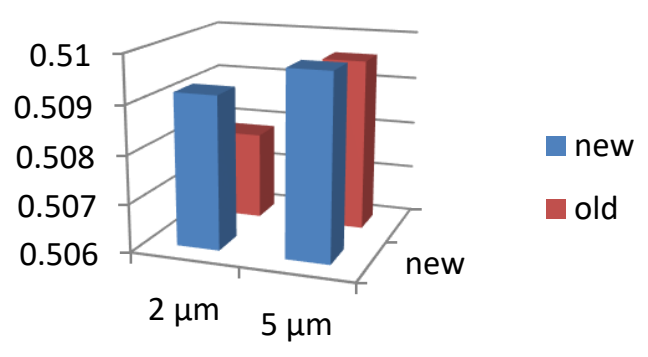

Graph 3. Graphic evaluation of Ra parameter

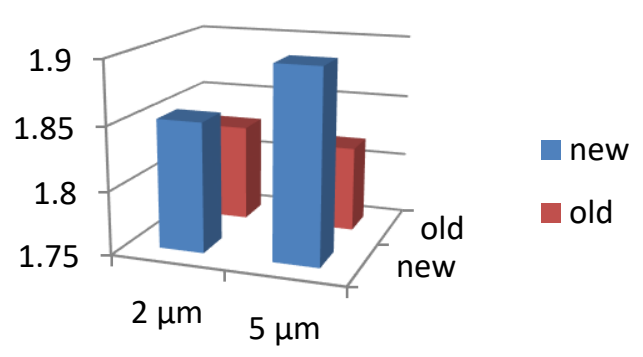

Graph 4. Graphic evaluation of Rz parameter

- $\mathrm{Rz}$ - "Sum of the height of the largest profile peak height and the largest profile valley depth within a sampling length." [4]

\begin{tabular}{|c|c|c|}
\hline & $\mathbf{2} \boldsymbol{\mu m}$ & $\mathbf{5} \boldsymbol{\mu m}$ \\
\hline difference in \% & 5.338913264 & 5.658038097 \\
\hline
\end{tabular}

Table 9. Percent difference between the new and the old stylus tip

\begin{tabular}{|c|c|c|}
\hline & New & Old \\
\hline difference in \% & -2.564967938 & -1.19364718 \\
\hline
\end{tabular}

Table 10. Percent difference between the $2 \mu \mathrm{m}$ and $5 \mu \mathrm{m}$ stylus tips

\subsubsection{Interim summary}

The differences between values of surface roughness parameters (i.e. R parameters) measured by $2 \mu \mathrm{m}$ and $5 \mu \mathrm{m}$ styli are neither large nor significant. With all the parameters, including those not listed here, the percent differences were under $1 \%$. It is not so when one evaluates surface profile parameters (i.e. P parameters). Here, the differences become more notable. Ordinarily, they reach 5\% but there are exceptions, such as with the Pa parameter in this article.

The differences between values measured by styli of different sizes are less than the differences between values from old and new styli. Although manufacturers of the equipment claim the stylus tips do not wear, some differences were expected even before starting this experiment. However, the differences found were larger than expected. With profile parameters, they reach as much as $20 \%$. With roughness parameters, they are lower. Yet, the resulting difference of around $5 \%$ is appreciable, given the importance of each micrometre. 


\subsection{Ra 1 standard}

The roughness of this standard represents a value which is ordinarily prescribed and used in practice. This standard, too, has an exclusively periodic surface. The value of the Rsm parameter which governed this test was in the middle of the interval required for this test. The value was $\mathrm{Rsm}=0.254 \mu \mathrm{m}$, which was ideal for this test.

\subsubsection{Profile parameters}

- $\mathrm{Pt} \quad$ - "Sum of the height of the largest profile peak height and the largest profile valley depth within the sampling length." [12]

\begin{tabular}{|c|c|c|}
\hline & $\mathbf{2} \boldsymbol{\mu m}$ & $\mathbf{5} \boldsymbol{\mu m}$ \\
\hline difference in $\%$ & 2.429639298 & 3.273100033 \\
\hline
\end{tabular}

Table 1. Percent difference between the new and the old stylus tip

\begin{tabular}{|c|c|c|}
\hline & New & Old \\
\hline difference in $\%$ & -2.71021078 & -2.64078042 \\
\hline
\end{tabular}

Table 2. Percent difference between the $2 \mu \mathrm{m}$ and $5 \mu \mathrm{m}$ stylus tips
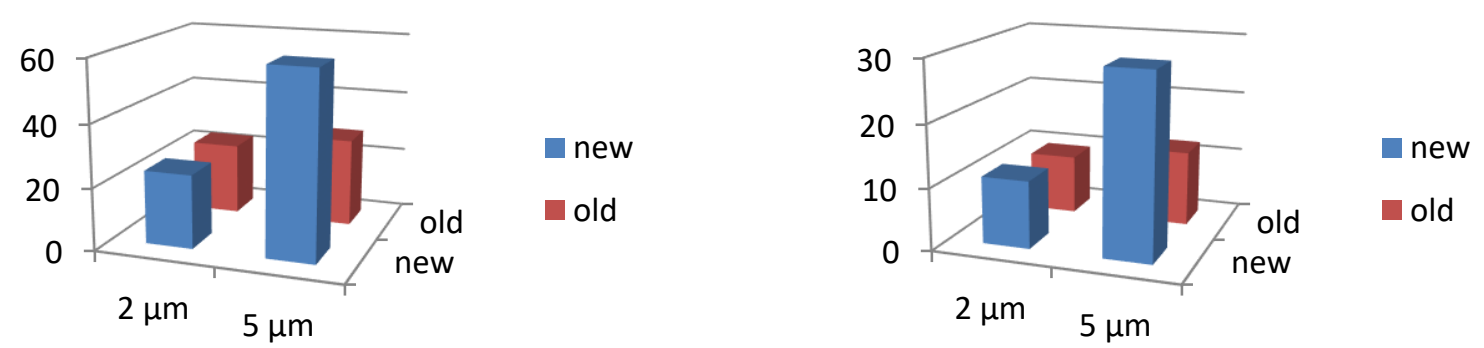

Graph 5. Graphic evaluation of Pt parameter

Graph 6. Graphic evaluation of Pa parameter

- $\quad \mathrm{Pa}$ - "Arithmetic mean of absolute ordinate values within a sampling length." [12]

\begin{tabular}{|c|c|c|}
\hline & $\mathbf{2} \boldsymbol{\mu m}$ & $\mathbf{5} \boldsymbol{\mu m}$ \\
\hline difference in $\%$ & 0.82355674 & 2.22645922 \\
\hline
\end{tabular}

Table 3. Percent difference between the new and the old stylus tip

\begin{tabular}{|c|c|c|}
\hline & New & Old \\
\hline difference in $\%$ & -1.89526753 & -1.80516959 \\
\hline
\end{tabular}

Table 4. Percent difference between the $2 \mu \mathrm{m}$ and $5 \mu \mathrm{m}$ stylus tips

\subsubsection{Roughness parameters}

The following parameters were chosen:

- $\mathrm{Ra}$ - "Arithmetic mean of absolute ordinate values within a sampling length." [12]

\begin{tabular}{|c|c|c|}
\hline & $\mathbf{2} \boldsymbol{\mu m}$ & $\mathbf{5} \boldsymbol{\mu m}$ \\
\hline difference in $\%$ & 1.414392181 & 0.42639593 \\
\hline
\end{tabular}

Table 5. Percent difference between the new and the old stylus tip 


\begin{tabular}{|c|c|c|}
\hline & New & Old \\
\hline difference in $\%$ & -0.285074323 & -1.290102123 \\
\hline
\end{tabular}

Table 6. Percent difference between the $2 \mu \mathrm{m}$ and $5 \mu \mathrm{m}$ stylus tips

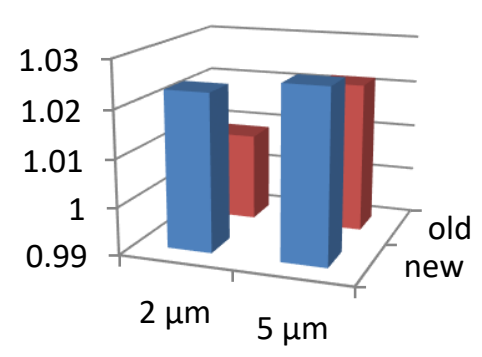

Graph 7. Graphic evaluation of Ra parameter

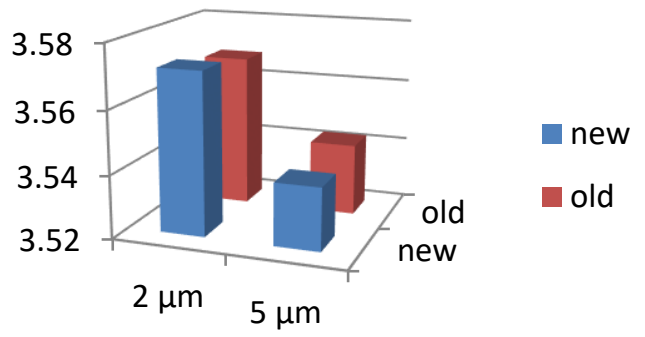

Graph 8. Graphic evaluation of Rz parameter

- $\mathrm{Rz}$ - "Sum of the height of the largest profile peak height and the largest profile valley depth within a sampling length." [12]

\begin{tabular}{|c|c|c|}
\hline & $\mathbf{2} \boldsymbol{\mu m}$ & $\mathbf{5} \boldsymbol{\mu m}$ \\
\hline difference in $\%$ & 0.084792627 & -0.082396563 \\
\hline
\end{tabular}

Table 7. Percent difference between the new and the old stylus tip

\begin{tabular}{|c|c|c|}
\hline & New & Old \\
\hline difference in \% & 0.886659278 & 0.72081186 \\
\hline
\end{tabular}

Table 8. Percent difference between the $2 \mu \mathrm{m}$ and $5 \mu \mathrm{m}$ stylus tips

\subsubsection{Interim summary}

The values collected with stylus tips of different sizes were compared. The differences in surface roughness readings (R parameters) from stylus tips of 2 and $5 \mu \mathrm{m}$ size were negligible. With all the parameters, including those not listed here, the percent differences were under $1 \%$. The differences in profile parameters (i.e. P parameters) are smaller for the Ra $1 \mu \mathrm{m}$ standard than for the Ra $0.5 \mu \mathrm{m}$ one. Here, the typical difference is $2-3 \%$.

In this case, the difference between the old and new stylus tips disappears, somewhat unexpectedly after the findings from the standard with a lower value. The differences found here are several tenths of percent which represents rather negligible distortion of measurement readings.

\subsection{Ra 3.2 standard}

This standard had the highest roughness value in this test. Its surface was periodic, as in the previous cases. Its Rsm value was outside the desired interval by a small margin. Nevertheless, the findings were used for showing how the need for correct stylus tip identification rises with increasing roughness value. The parameter value was Rsm $=0.408 \mu \mathrm{m}$.

\subsubsection{Profile parameters}

- Pt - "Sum of the height of the largest profile peak height and the largest profile valley depth within the sampling length." [12]

\begin{tabular}{|c|c|c|}
\hline & $\mathbf{2} \boldsymbol{\mu m}$ & $\mathbf{5} \boldsymbol{\mu m}$ \\
\hline difference in \% & 32.931900778 & 31.908741288 \\
\hline
\end{tabular}

Table 9. Percent difference between the new and the old stylus tip 


\begin{tabular}{|c|c|c|}
\hline & New & Old \\
\hline difference in \% & 0.666839942 & -0.380194729 \\
\hline
\end{tabular}

Table 10. Percent difference between the $2 \mu \mathrm{m}$ and $5 \mu \mathrm{m}$ stylus tips

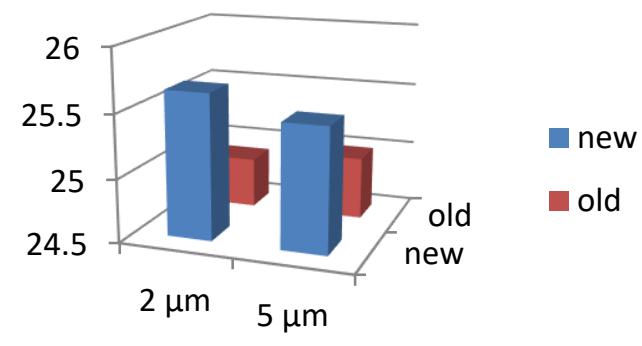

Graph 9. Graphic evaluation of Pt parameter

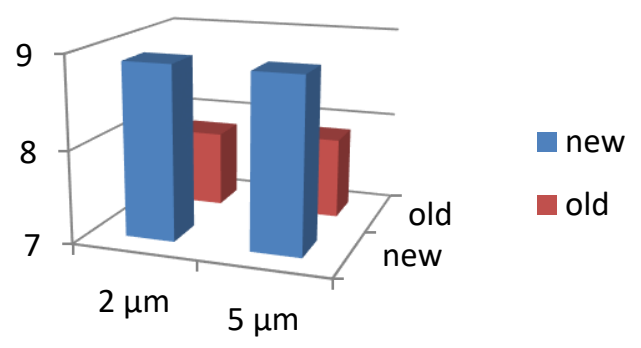

Graph 10. Graphic evaluation of Pa parameter

- $\quad \mathrm{Pa}$ - "Arithmetic mean of absolute ordinate values within a sampling length." [12]

\begin{tabular}{|c|c|c|}
\hline & $\mathbf{2} \boldsymbol{\mu m}$ & $\mathbf{5} \boldsymbol{\mu m}$ \\
\hline difference in $\%$ & 31.90680923 & 31.18939696 \\
\hline
\end{tabular}

Table 11. Percent difference between the new and the old stylus tip

\begin{tabular}{|c|c|c|}
\hline & New & Old \\
\hline difference in \% & 0.161789533 & -0.651271682 \\
\hline
\end{tabular}

Table 12. Percent difference between the $2 \mu \mathrm{m}$ and $5 \mu \mathrm{m}$ stylus tips

\subsubsection{Roughness parameters}

The following parameters were chosen:

- Ra - "Arithmetic mean of absolute ordinate values within a sampling length." [12]

\begin{tabular}{|c|c|c|}
\hline & $\mathbf{2} \boldsymbol{\mu m}$ & $\mathbf{5} \boldsymbol{\mu m}$ \\
\hline difference in $\%$ & 31.057187017 & 30.643301276 \\
\hline
\end{tabular}

Table 13. Percent difference between the new and the old stylus tip

\begin{tabular}{|c|c|c|}
\hline & New & Old \\
\hline difference in \% & 0.225399279 & -0.191965897 \\
\hline
\end{tabular}

Table 14. Percent difference between the $2 \mu \mathrm{m}$ and $5 \mu \mathrm{m}$ stylus tips

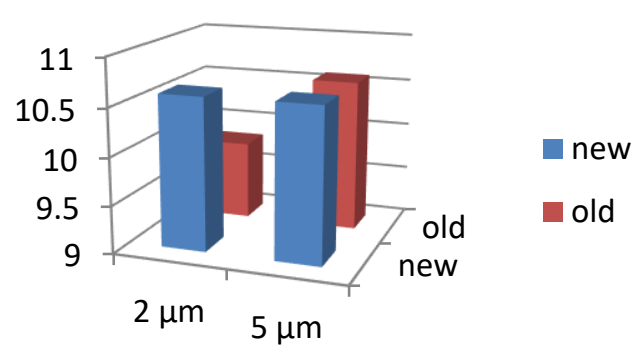

Graph 11. Graphic evaluation of Ra parameter

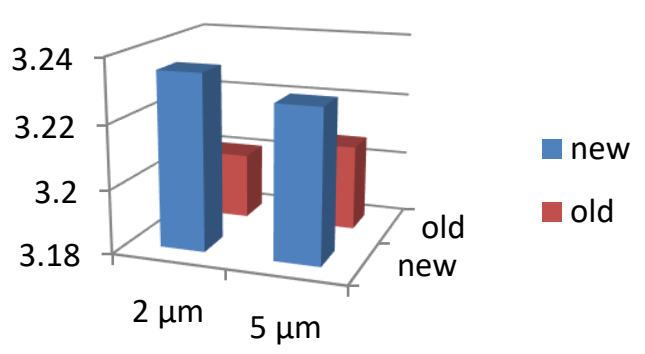

Graph 12. Graphic evaluation of Rz parameter 
- $\mathrm{Rz}$ - "Sum of the height of the largest profile peak height and the largest profile valley depth within a sampling length." [4]

\begin{tabular}{|c|c|c|}
\hline & $\mathbf{2} \boldsymbol{\mu m}$ & $\mathbf{5} \boldsymbol{\mu m}$ \\
\hline difference in $\%$ & 7.275296338 & 3.140746414 \\
\hline
\end{tabular}

Table 15. Percent difference between the new and the old stylus tip

\begin{tabular}{|c|c|c|}
\hline & New & Old \\
\hline difference in $\%$ & -0.094356313 & -7.795952047 \\
\hline
\end{tabular}

Table 16. Percent difference between the $2 \mu \mathrm{m}$ and $5 \mu \mathrm{m}$ stylus tips

\subsubsection{Interim summary}

The graphs clearly show that values obtained with both styli are nearly identical. This holds for both roughness parameters (R parameters) and profile parameters ( $\mathrm{P}$ parameters). With all the parameters, the percent differences were under $1 \%$.

However, those between old and new styli were rising sharply. In this test, they even exceeded $30 \%$. This is a value which is unthinkable in precision measurement.

\section{Conclusion}

Today's demands on high-speed components are increasing, giving rise to a need for measuring geometric parameters and deviations and even surface integrity parameters in such components. This is one of the reasons why measurement and evaluation of surface texture have seen major qualitative advances in recent years. Leading producers of measuring instruments (Hommel, Carl Zeiss, and others) have responded actively to new requirements. They did so despite the fact that surface texture is frequently measured and evaluated by means of single-purpose measuring machines - and developed new machines, equipment, methods, standards and guidelines.

The purpose of this article was to map at least a small part of this field. It describes an analysis of the effects that the size and shape of a stylus tip has on the readings that characterize surface texture elements. The results of this research will be further used and implemented in the design of methods for the selection of software filters for roughness measurement.

The tests were carried out using the Hommel Etamic T8000 machine housed at the Regional Technological Institute affiliated with the University of West Bohemia. Styli with two tip radii (2 and $5 \mu \mathrm{m})$ with an apex angle of $90^{\circ}$ were employed. The styli tested were part of new and used probe arms. Test pieces were roughness standards of nominal values of $\mathrm{Ra}=0.5 ; 1 ; 3.2 \mu \mathrm{m}$. Surface texture parameters were calculated with a robust Gaussian filter. Each standard was divided into 12 fields of $10 \times 6 \mathrm{~mm}$ size. Four primary profiles were measured in each field. These measurement runs were repeated twice. This test is planned to be repeated in the future on higher and lower-roughness surfaces.

The data were evaluated in several steps. In the first step, the parameter values were averaged across the entire standard and for the particular stylus tip. These values are plotted in graphs here. In the second step, the percent differences between values of selected parameters were calculated. These were values measured with stylus tips of the same size but different wear levels. The values measured with the new stylus tip were taken as the reference values. In the third step, the percent difference between stylus tips with the same wear level but different tip radii was calculated. The reference value was the value measured with the stylus tip of $2 \mu \mathrm{m}$ size.

Results that characterize the effect of the stylus tip radius can be divided into two groups. The first group comprises the profile parameters (P parameters). Their calculation is not affected by any filter. They are an effective indicator of the impact of the stylus tip radius. With all three standards, the differences between these parameters were under $3 \%$. The second group consists of roughness parameters (R parameters). These are demanded by customers much more often than those of the former group. To calculate them, one has to use mathematical formulae to separate (filter) them from the primary profile. It is a source of a certain percent error. It also distorts any errors introduced by an inadequate choice of a stylus tip radius. Here, the percent difference was under $1 \%$. This is a very favourable finding but caution should be exercised, considering the filter used. With the 2RC filter, these values in the second group reach 5-8\%.

Nevertheless, these values, too, are negligible when compared to the differences between data from used and new styli. Some difference was expected there, despite manufacturers' claims that styli do not suffer any wear. However, most of the differences found were larger than expected. With profile parameters, they reached as much as $20 \%$. With roughness parameters, the value was less extreme. Still, the final difference of about $5 \%$ is appreciable in the field where every micrometre matters. 


\section{Acknowledgments}

The article has been prepared in the project LO1502 'Development of the Regional Technological Institute" under the auspices of the National Sustainability Programme I of the Ministry of Education of the Czech Republic aimed to support research, experimental development and innovation.

\section{References}

[1] ISO/TS 16610-1 Technical specification ISO/TS 16610. Geometrical product specifications (GPS) - Filtration, 2015.

[2] ČSN EN ISO 16610-20. Geometrical product specifications (GPS) - Filtration - Part 20: Linear profile filters: Basic concepts. Brussels: ÚNMZ, 2015.

[3] ČSN ISO/TS 16610-21 Geometrical product specifications (GPS) - Filtration - Part 21: Linear profile filters: Gauss filters. Brussels: ÚNMZ, May 2012

[4] ČSN EN ISO 16610-40. Geometrical product specification (GPS) - Filtration - Part 40: Morphological profile filter: Basic concepts, 2016

[5] ČSN EN ISO 4287. Geometrical product specification (GPS) - Surface structure: Profile method - Terms, definitions and surface texture parameters - Part 1; Brussels: CEN, 1999.

[6] http://www.hommel-etamic.cz/cz/technicke-informace/drsnost-povrchu-dle-din-en-iso/ [online]. [2016-08-27]

[7] http://www.techno-mat.cz/data/katedry/kom/KOM_MM_PR_10_CZE_Karasek _Geometricke_vlastnosti_povrchu.pdf [online]. [cit. 2015-02-01].

[8] https://www.olympus-ims.com/en/knowledge/metrology/roughness/[online]. [cit. 2015-09-01].

[9] https://www.hommel-etamic.cz/files/2009-13_en_roughness_poster.pdf[online]. [cit. 2015-09-01].

[10] Melichar M., Kutlwašer J.,Kubátová D.: (2016). Effect of Sweat Aggressiveness on Parameters of Surface Integrity. , 0536. DOI: 10.2507/26th.daaam.proceedings.073. Available at: http://www.daaam.info/Downloads/Pdfs/proceedings/proceedings_2015/073.pdf

[11] E.S. Gadelmawla, M.M. Koura, T.M.A. Maksoud, I.M. Elewa, H.H. Soliman,: (2002) Roughness parameters, In Journal of Materials Processing Technology, Volume 123, Issue 1, , Pages 133-145, ISSN 0924-0136, https://doi.org/10.1016/S0924-0136(02)00060-2.

Dostupné také z:http://www.sciencedirect.com/science/article/pii/S0924013602000602

[12] E.Clayton Teague, Fredric E. Scire, Saul M. Baker, Stephen W. Jensen, (1982)Three-dimensional stylus profilometry, In Wear, Volume 83, Issue 1, , Pages 1-12, ISSN 0043-1648, https://doi.org/10.1016/00431648(82)90335-0. Available at:http://www.sciencedirect.com/science/article/pii/0043164882903350

[13] M. Shah Mohammadi, M. Ghani, M. Komeili, B. Crawford, A.S. Milani,( 2017) The effect of manufacturing parameters on the surface roughness of glass fibre reinforced polymer moulds, In Composites Part B: Engineering, Volume 125, Pages 39-48, ISSN 1359-8368, https://doi.org/10.1016/j.compositesb.2017.05.028. Available at: http://www.sciencedirect.com/science/article/pii/S1359836816317887) 